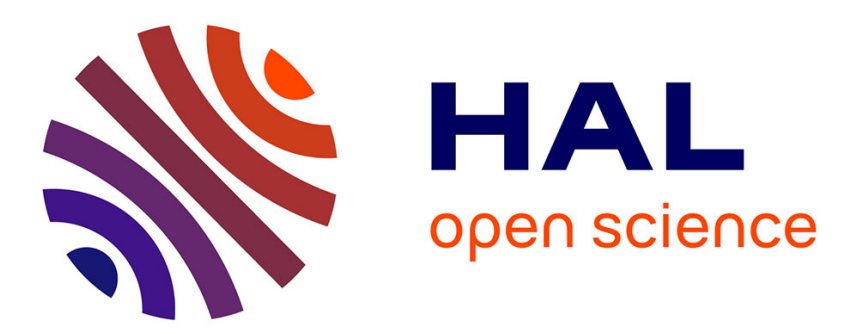

\title{
Estimating extreme sea levels combining systematic observed skew surges and historic record sea levels
}

Laurie Saint Criq, Yasser Hamdi, Eric Gaume, Taha Ouarda

\section{To cite this version:}

Laurie Saint Criq, Yasser Hamdi, Eric Gaume, Taha Ouarda. Estimating extreme sea levels combining systematic observed skew surges and historic record sea levels. European Geosciences Union General Assembly, vEGU21, Apr 2021, VIRTUAL, Austria. 2021. hal-03431752

\section{HAL Id: hal-03431752 \\ https://hal.science/hal-03431752}

Submitted on 16 Nov 2021

HAL is a multi-disciplinary open access archive for the deposit and dissemination of scientific research documents, whether they are published or not. The documents may come from teaching and research institutions in France or abroad, or from public or private research centers.
L'archive ouverte pluridisciplinaire HAL, est destinée au dépôt et à la diffusion de documents scientifiques de niveau recherche, publiés ou non, émanant des établissements d'enseignement et de recherche français ou étrangers, des laboratoires publics ou privés.

$$
\text { Copyright }
$$




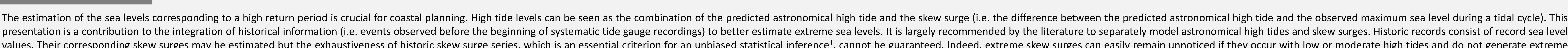

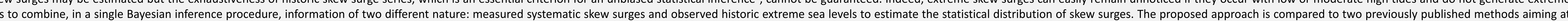
sea levels. ${ }^{2}$. This study proposes to combine, in a sil
valuating historical reconstructed skew surges $5^{3,4}$.

\section{PROPOSED MODEL}

$$
\begin{aligned}
& \text { - The global likelihood expression of systematic skew surges and historic sea levels } \\
& \text { Extreme skew surges above the threshold } u \text { are chosen to be modelled by } \\
& \text { a General Pareto (GP) distribution: } \\
& \qquad \forall x>u, F_{\theta}(x)= \begin{cases}1-\left[1+\xi \frac{(\xi-u)}{\sigma}\right]^{-\frac{1}{\xi}}, & \xi \neq 0, \\
1-\exp \left(-\frac{x-u}{\sigma}\right), & \xi=0 .\end{cases} \\
& \text { where } \theta=(\sigma, \xi) \text { are the scale }(\sigma>0) \text { and shape }(\xi \in \mathbb{R}) \text { parameters. } \\
& \text { - The likelihood formulation of systematic skew surges }(>u) \text { is: } \\
& \qquad \boldsymbol{L}\left(\boldsymbol{X}_{\boldsymbol{s} y \boldsymbol{s}} \mid \boldsymbol{\theta}, \lambda\right)=\boldsymbol{P}_{\boldsymbol{\lambda}}(\boldsymbol{N}=\boldsymbol{n}) \prod_{i=1}^{n} \boldsymbol{f}_{\boldsymbol{\theta}}\left(\boldsymbol{x}_{\boldsymbol{s y s}, \boldsymbol{i}}\right) \\
& \text { with } f_{\boldsymbol{\theta}} \text { the } G \mathrm{P} \text { density function. } \\
& \text { The number of systematic skew surges exceeding } u \text { during the systematic } \\
& \text { period } w_{S} \text { follows a Poisson process of intensity } 2 w_{S} \text {. }
\end{aligned}
$$

\section{METHOD}

- Data and Monte Carlo simulations

作

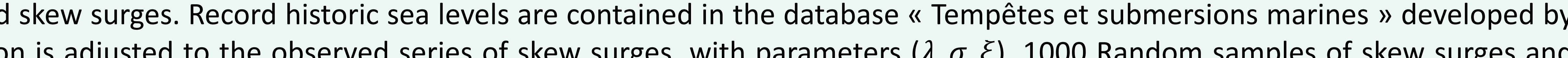
maximum sea levels (after a convolution with the empirical series of observed high tides), with the same characteristics than the observed systematic and historical series are then generated through Monte Carlo simulations, to test the proposed statistical estimation method.

- Properties of the estimated 100-year quantile and parameters with maximum likelihood (ML) The estimated 100-year quantiles

- Reliability of the posterior credibility interval

作 exceedance probability of the real quantile $P\left(\hat{Q}_{100}<Q_{100}\right)$, according to the computed credibility intervals for each random sample. $P\left(\hat{Q}_{100}<Q_{100}\right)$ should be uniformly distributed if the credibility intervals are reliable. A] the $N-h$ ordinary historical sea levels that did not exceed $\eta_{H} \ldots$ during the historical period

$$
L\left(Z_{\text {hist }} \mid \theta, \lambda\right)=\underbrace{G_{\theta, \lambda}\left(\eta_{H}\right)^{N-h}}_{[\mathrm{A}]} \underbrace{\left.1-G_{\theta, \lambda}\left(\eta_{H}\right)\right]^{h} \prod_{i=1}^{h} \frac{g_{\theta, \lambda}\left(Z_{h i s t, i}\right)}{1-G_{\theta, \lambda}\left(\eta_{H}\right)}}
$$

[B] Whctions of sea levels which can be numerically computed given the statistical

\section{CASE STUDY AND RESULTS}

- Systematic period (1941- 2017): $w_{S}=32.58$ years, $\mu=0.62 \mathrm{~m}, n=34$ - Historical period $(1941-2017) . w_{S}=32.58 \mathrm{yeas}, \mu=0.62 \mathrm{~m}, n=34$

Where $g_{\theta, \lambda}$ and $G_{\theta, \lambda}$ are respectively the density and the cumulative distribution dstributions of the skew surges and of the maximum astronomical tidal levels.

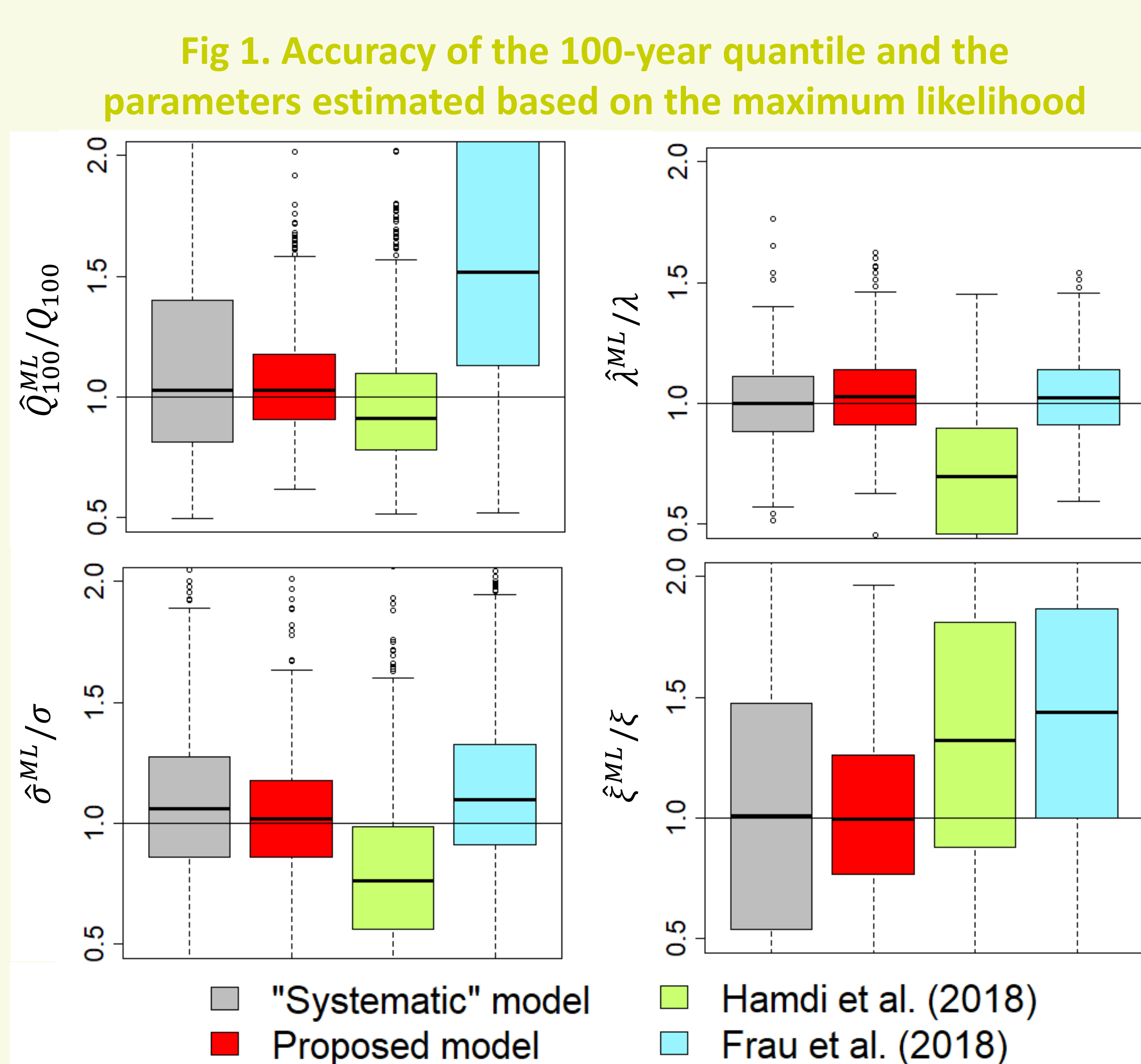

The proposed model provides unbiased estimates with the ML compared to the previously shape parameter $\xi$ of the skew surge distribution.

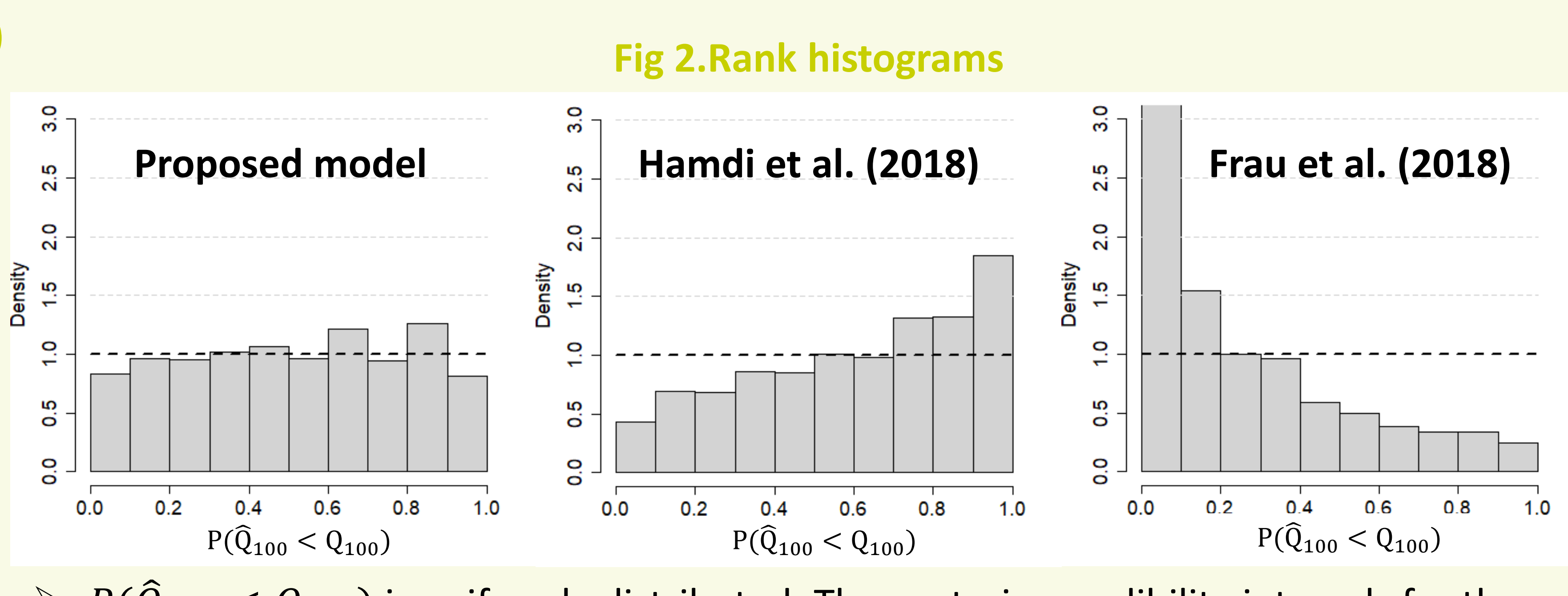
100-year quantile seem accurate with the proposed model but not with the previously published methods.

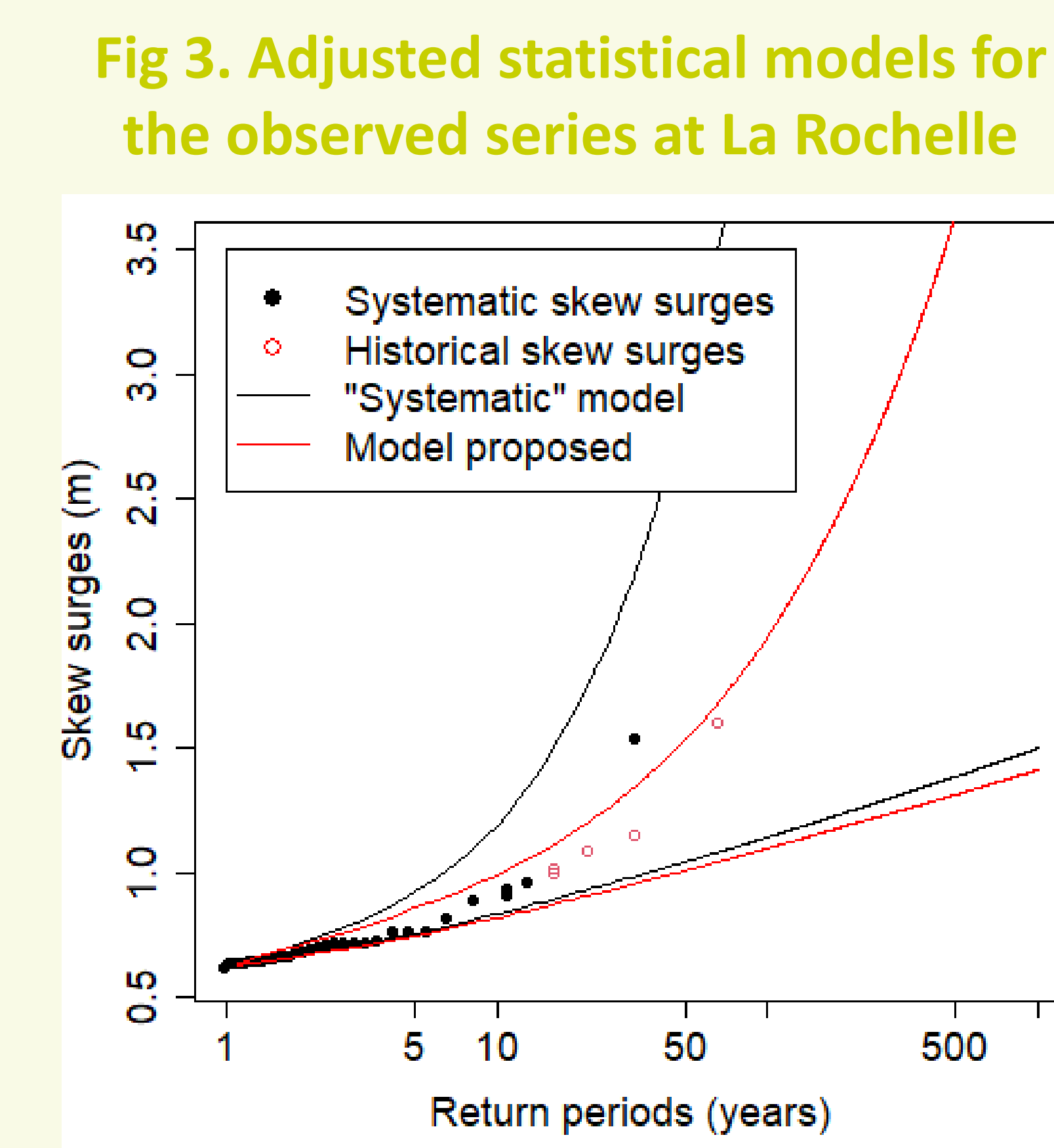

The credibility intervals obtaine with the proposed approach well Integrating historic sea levels with decrease the width of the decrease the width of
credibility intervals.

\section{CONCLUSION}

$>$ The proposed approach combines, in a single Bayesian inference, skew surges for the recent period and record sea levels for the historical period.

$\rightarrow$ It has been successfully tested and applied to four different sites located on the French Channel and Atlantic coast (La Rochelle illustrated here). Unlike some other previously published methods, it provides unbiased quantile estimates and accurate credibility intervals.
For more detals,

References
1E. Gaume, "Flood frequency analysis: The Bayesian choice", Wiley Interdis-cilinary Reviews: Water 5 (2018), 10.1002/wat2.1290
2S. Outten et al al, "Re-assessing extreme sea level events through interplay of tides and storm surges" (2020), 10.5194//egusphere-

2. Outten et al., "Re-assessing extreme sea level events through interplay of tides and storm surges" (2020), 10.5194/egusphere- egu2020-8000
3Y. Hamdi et al., "Use of historical information in extreme-surge frequency estimation: the case of marine flooding on the La Rochelle site in France" (2015), 10.5194/nhess-15-1515-2015

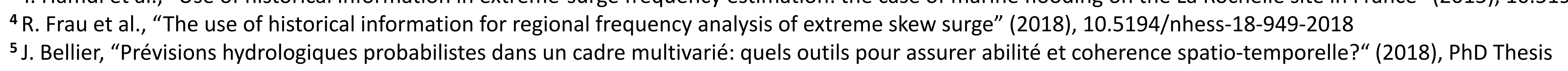

